\title{
Optimal Site and Size of Distributed Generator in Distribution Network Con- sidering Active Power Loss Minimization
}

\author{
Aamir Ali ${ }^{1, *}$, M. Usman Keerio ${ }^{1}$, Noor Hussain Mugheri ${ }^{1}$, Munawar Ayaz Memon ${ }^{1}$, Erum Pathan ${ }^{2}$ \\ ${ }^{1}$ Department of Electrical Engineering, QUEST, Nawabshah, Pakistan. \\ ${ }^{2}$ Department of Electronic Engineering, QUEST, Nawabshah, Pakistan. \\ ${ }^{*}$ Corresponding author: aamirali.bhatti@quest.edu.pk
}

Abstract

Distributed Generation (DG) allocation in distribution network is an optimal choice in maximizing benefits and reducing power losses. In this paper, self-adaptive differential evolution (SaDE), an optimization approach, is used for optimal site and capacity of DG. Different types of DGs such as solar PV and wind turbine (WT) at constant and near unity power factor are integrated into the distribution system. For validation of the proposed algorithm, IEEE 33-bus, 69-bus and 119-bus radial distribution networks are considered. The results show that the proposed algorithm has the ability to find global minimum value of objective function along with the appropriate site and capacity of solar PV and WT type DG. Moreover, the results of proposed method are compared with other existing techniques in order to show its effectiveness. The comparison shows that the proposed technique has the ability to get the lowest power losses with the smallest DG size. Thus, the proposed technique has the ability to find an optimal decision vector that makes it suitable for real-time applications.

Keywords-Differential Evolution, Distributed Generator, Radial Distribution Network, Power loss, Solar PV and Wind

\section{Introduction}

$\mathrm{D}$ ISTRIBUTED generation (DG) technology is getting importance because of the technological revolution, regulatory environment and changing economic conditions. Various issues have been accountable for the use of DG in distribution network (RDN), such as saving cost by the peak use of the capacity, improvement in reliability, security and power quality, use for local networks, support grid (DGs provide necessary support to the primary activities or operation of grid), reduction in power losses, and environmental concerns to decrease greenhouse gas emission. However, if the size and position of DG are not determined appropriately in RDN, this may effect several counterproductive effects such as high financial cost, increase in real power losses, variation in voltage profile along the network, increase short circuit capacity, protection issues, sudden transients in voltage [1][2]. Therefore, in order to optimize these benefits and overcome counter effects, optimal size of DGs along with optimal alloca-

ISSN: 2523-0379 (Online), ISSN: 1605-8607 (Print)

DOI: 10.52584/QRJ.1802.02

This is an open access article published by Quaid-e-Awam University of Engineering Science $\&$ Technology, Nawabshah, Pakistan under CC BY 4.0 International License. tion are extremely important. Thus, optimal allocation of DG has been considered as a global issue both for academic as well as industry sector.

Therefore, a plethora of research has been conducted for the optimal DG allocation. Some of the notable techniques using analytical approach to enhance profile of voltage and minimization of real power losses considering different load models have been outlined in [3][9]. As compared to single DG integration analytical problem formulation, multiple DG allocation produced further complexities. Recently, advanced computational intelligence (CI) leads to the development of evolutionary techniques. In the literature, evolutionary algorithms have been implemented successfully to find the appropriate DGs allocation in radial networks. These includes, Genetic algorithm (GA), Differential Evolution (DE), Ant Colony Optimization (ACO), Artificial Bee Colony (ABC) algorithms, to name a few. Some notable techniques for the solution of DG allocation problem using GA algorithm and PSO algorithm are reported in [10][13][14]. Furthermore, several methods such as Comprehensive Teaching Learning Cased Optimization (CTLBO) [15], hybrid ABC/ACO [16], Success History Based Adaptive DE (SHADE) 
[17], Cuckoo Search Algorithm (CSA) [18], and Fire Work Algorithm (FWA) [19] have been reported for the solution of DG allocation problem considering various standard IEEE test systems. In some metaheuristic approaches, proposed in [20][21][11], sensitivity indices are adapted to reduce the dimensions of decision vector and hence the search space. These indices sort the nodes in descending order with respect to bus voltage and select the first few nodes equivalent to the number of DGs for the placement of DG.

In this paper, an optimization approach (SaDE) is applied for finding the best site and appropriate capacity of DG. Various standard RDNs, 33bus, 69-bus and 119-bus are considered for the injection of wind and solar type of single and multiple DGs. Furthermore, results of $\mathrm{SaDE}$ are compared with other approaches to show its effectiveness.

The organization of rest of the paper is as follows. Section II presents the problem formulation. Modelling of wind and solar PV is mentioned in section III. The proposed SaDE optimization method is discussed in section IV. Some case studies are discussed in section V. Section VI and Section VII present results and a thorough discussion on them. Section VIII concludes the paper.

\section{Problem Formulation}

Optimal site and capacity of DGs, namely Solar PV and WT, are considered. The purpose of this study is to reduce RPL along with enhancement in voltage profile. Load flow method, objective function, constraints and proposed SaDE algorithm are presented in the following sections.

\subsection{Power Flow Problem Formulation}

Gauss Seidel (GS) and Newton Raphson (NR) techniques are not appropriate for the calculation of voltage at each bus and its due small value of $\mathrm{X} / \mathrm{R}$ ratio, weakly meshed configuration and large number of nodes. Hence, load flow is considered by means of forward-backward sweep method that is effective for RDNs. In this technique, swing bus is represented as source and other buses are injected through slack bus as shown in Figure 1. In this technique, value of voltage and current can be computed using Kirchhoff's laws. Considering a branch among bus $i$ and $j$ of the typical distribution network as shown in Figure 1, following are the main steps of FBS load flow method [22]. First of all, select the reference bus and assume the magnitude of reference bus $|V|=1$ p.u and its angle $\delta=0^{\circ}$. During forward sweep, Equation 1 and

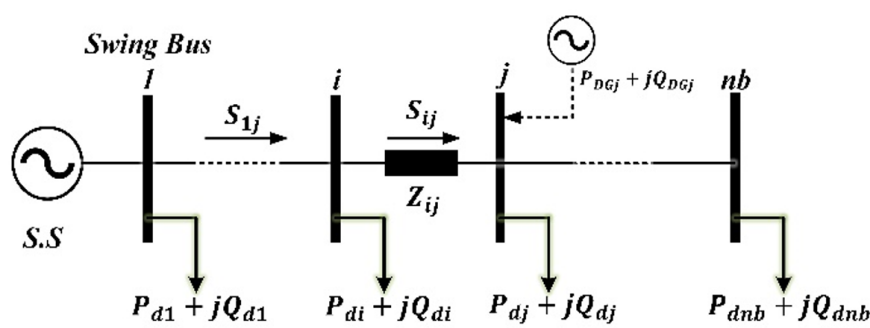

Fig. 1: Typical radial distribution network

Equation 2 are used to calculate approximate current and voltage as follows.

$$
\begin{aligned}
I_{i}^{k} & =\left[\frac{S_{i}^{k}}{V_{i}^{k-1}}\right]^{*} \\
V_{j}^{k-1} & =V_{i}^{k}-Z_{i j} I_{i}^{k}
\end{aligned}
$$

Where,

$I_{i}^{k}$ : Current injection at bus i, during $k^{\text {th }}$ iteration

$S_{i}^{k}$ : Power injection at bus i during $k^{\text {th }}$ iteration

$V_{i}, V_{j}$ : Sending and receiving end bus voltages

$Z_{i j}$ : Impedance of branch between bus $i$ and $j$

During backward sweep, value of current is calculated by simply algebraic sum of line currents from last lower branch up to source using Equation 3.

$$
I_{i}^{k}=I_{j}^{k}+\sum_{m=1}^{l} I_{m}^{k}
$$

Where,

$I_{m}^{k}$ : entire current of parallel branches connected to main bus $\mathrm{m}$ at $k^{\text {th }}$ iteration

$n l$ : number of branches

After the calculation of line current, updated node voltages are calculated and the process of convergence is examined using Equation 4 and Equation 5.

$$
\begin{gathered}
V_{j}^{k}=V_{i}^{k}-Z_{i j} I_{i}^{k} \\
\left|\Delta V_{i}^{k}\right|=\left|V_{i}^{k-1}\right|-\left|V_{i}^{k}\right| \leq \varepsilon_{v}
\end{gathered}
$$

Where, $\varepsilon_{v}$ : acceptable mismatch of voltage in $k^{t h}$ iteration. Finally, apparent power is computed using Equation 6 and mismatch of real and reactive power is calculated using Equation 7 and Equation 8 for convergence basis,

$$
\begin{gathered}
S_{i}^{k}=V_{i}^{k}\left(I_{i}^{k}\right)^{*} \\
\Delta P_{i}^{k}=\Re\left[S_{i}^{k-1}-S_{i}^{k}\right] \\
\Delta Q_{i}^{k}=\Im\left[S_{i}^{k-1}-S_{i}^{k}\right]
\end{gathered}
$$

Where,

$\Delta P_{i}^{k}$ : real power mismatch in $k^{t h}$ iteration,

$\Delta Q_{i}^{k}$ : imaginary power mismatch in the $k^{\text {th }}$ iteration. 


\subsection{Objective Function}

Total loss $\left(P_{\text {loss }}\right)$ is measured as objective function and mathematically can be defined as [23];

$$
\operatorname{minf}(x)=P_{\text {loss }}=\sum_{i=1}^{n b} \sum_{j=1}^{n l}\left|\left(\frac{V_{i}-V_{j}}{Z_{i j}}\right)\right|^{2} \times R_{i j}
$$

Where,

$P_{\text {loss }}$ : objective function

$R_{i j}$ : branch resistance

$n b:$ number of busses

$n l:$ number of branches

This paper considers two type of DGs, i.e. wind and solar PV. Wind type DG has the capability to inject both active and reactive power, whereas, solar PV injects only active power. DGs are considered as negative $\mathrm{PQ}$ load because they do not regulate the voltage as suggested in [24]. Active power $\left(P_{D G}\right)$ of DG connected to bus $i$ at loading $P_{L, i}$, is changed from $P_{L, i}$ to $\left(P_{L, i}-P_{D G}\right)$ and generation of its reactive power is calculated using Equation 10.

$$
Q_{D G, i}=P_{D G, i} \times \tan \left(\cos ^{-1}\left(p \cdot f_{D G, i}\right)\right)
$$

Hence, reactive power loading $Q_{L, i}$ at bus $i$ is changed to $Q_{L, i}-Q_{D G, i}$. The algorithm determines the solution of mixed integer problem such as DGs rating (continuous) and possible locations of DGs (discrete).

\subsection{Constraints}

Total power loss, calculated by using Equation 9, is minimized subjected to satisfying the following equality and inequality constraints.

\subsubsection{Equality Constraints}

MW and MVAr power balance are done during the load flow, mathematically these constraints given as:

$$
\begin{aligned}
& \sum_{i=1}^{n b} P_{g i}=\sum_{i=1}^{n b} P_{d i}+P_{\text {loss }} \\
& \sum_{i=1}^{n b} Q_{g i}=\sum_{i=1}^{n b} Q_{d i}+Q_{\text {loss }}
\end{aligned}
$$

Where,

$P_{g i}$ and $Q_{g i}:$ MW and MVAr injection

$P_{d i}$ and $Q_{d i}:$ MW and MVAr demand

\subsubsection{Inequality Constraints}

Voltage constraints: At each bus, voltage constraints can be represented as follows:

$$
\left|V_{i}^{\min }\right| \leq\left|V_{i}\right| \leq\left|V_{i}^{\max }\right|
$$

Where,

$\left|V_{i}^{\text {min }}\right|: 0.95$ p.u minimum value

$\left|V_{i}^{\max }\right|: 1.05$ p.u maximum value

Complex power flow constraints: Complex power flow constraint assures that the entire flow of complex power in the line must be within the safe limit given as below:

$$
\begin{gathered}
s_{i j}^{\text {rated }} \leq s_{i j}^{\max } \\
s s_{j i}^{\text {rated }} \leq s_{j i}^{\max }
\end{gathered}
$$

Where,

$s_{i j}^{\max }$ and $s_{j i}^{\max }$ : maximum complex powers flow $s_{i j}^{\text {rated }}$ and $s_{j i}^{\text {rated }}$ : rated complex power flow

$D G$ constraints: DGs size must be bound within desirable limit. If it is increased beyond a certain limit, losses also increase. Hence DG have some bounded above and below below limits as follows.

$$
\begin{gathered}
\sum_{i=1}^{N_{D G}}\left(P_{D G i}\right) \leq\left(\sum_{i=1}^{n b} P_{d i}+P_{\text {loss }}\right) \\
\sum_{i=1}^{N_{D G}}\left(Q_{D G i}\right) \leq\left(\sum_{i=1}^{n b} Q_{d i}+Q_{\text {loss }}\right) \\
P_{D G i}^{\min } \leq P_{D G i} \leq P_{D G i}^{\max } \\
Q_{D G i}^{\min } \leq Q_{D G i} \leq Q_{D G i}^{\max }
\end{gathered}
$$

Where,

$P_{D G i}^{\min } ; P_{D G i}^{\max }:$ maximum and minimum active power of DG.

$Q_{D G i}^{\min } ; Q_{D G i}^{\max }:$ minimum and maximum reactive power of DG.

$N_{D G}:$ number of DGs

\section{DG Modeling}

According to IEEE1547 standards [25], DGs must be operated at constant p.f near to unity. In this paper, non-conventional DGs such as solar PV (operating at unity p.f, generate active power only) and wind type DG (op-erating at 0.85 to 0.95 ) lagging p.f, both are considered as negative PQ load model. 


\subsection{Modeling of Solar PV Type DG}

Solar PV power is the function of solar irradiance $(G)$. Therefore, relationship among available power of solar $\mathrm{PV}$ and solar irradiance is computed as [26]:

$$
P_{p v}=\left\{\begin{array}{crl}
P_{p v r} \times\left(\frac{G}{G_{r}}\right) & 0 \leq G & \leq G_{r} \\
P_{p v r} & G_{r} & \leq G
\end{array}\right.
$$

Where,

$G_{r}$ and $G$ : solar radiations in $W / m^{2}$ at chosen location and at surface of earth, $P_{p v r}$ : output of PV at $25^{\circ}$ and solar radiation at $1000 \mathrm{~W} / \mathrm{m}^{2}$.

\subsection{Modelling of Wing Turbine (WT) Type DG}

In WT type DG, generated power is the function of uncertain wind speed (v) and can be modelled as:

$$
P_{w}=\left\{\begin{array}{cc}
0, & \text { if } 0 \leq v \leq v_{\text {cin }}, \text { or } v \geq v_{\text {out }} \\
P_{w r} \times\left(\frac{v-v_{\text {cin }}}{v_{r}-v_{\text {cin }}}\right), & v_{\text {cin }} \leq v \leq v_{r} \\
P_{w r}, & v_{r} \leq v \leq v_{\text {out }}
\end{array}\right.
$$

Where:

$v$ : available wind speed

$v_{\text {cin }}, v_{r}, v_{\text {out }}$ : cut in, rated and cut out speeds

$P_{w r}:$ rated power

\section{Self-Adaptive Differential Evolution}

Price and Storn first introduced DE which is a population based stochastic optimization technique, extensively applied in many engineering applications [27]. Performance of DE mainly depends on trial vector generation strategy and control parameters (i.e. population $N_{p}$, scaling factor $F$ and crossover $\mathrm{CR}$ ). Details of SaDE algorithm are given in Figure 2 , and its main parts are defined in the subsequent sections.

\subsection{Initialization}

Initially, decision variable, using Equation (22), is randomly generated from the feasible bounds of decision parameters and is uniformly distributed overt the entire search space. At generation $G=0$, the value of $j t h$ decision vector in the $i t h$ population is produced as:

$$
X_{i, 0}^{j}=X_{\min }^{j}+\operatorname{rand}(0,1)\left(X_{\max }^{j}-X_{\min }^{j}\right)
$$

Where, $i=1, \ldots, N_{p} ; j=1, \ldots$, D $N_{p}$ : initial population, $D$ : decision vector, $X_{\min }^{j}$ and $X_{\max }^{j}:$ minimum and maximum bound parameters, rand $(0,1)$ : random variables uniformly distributed overt the range of $[0,1]$

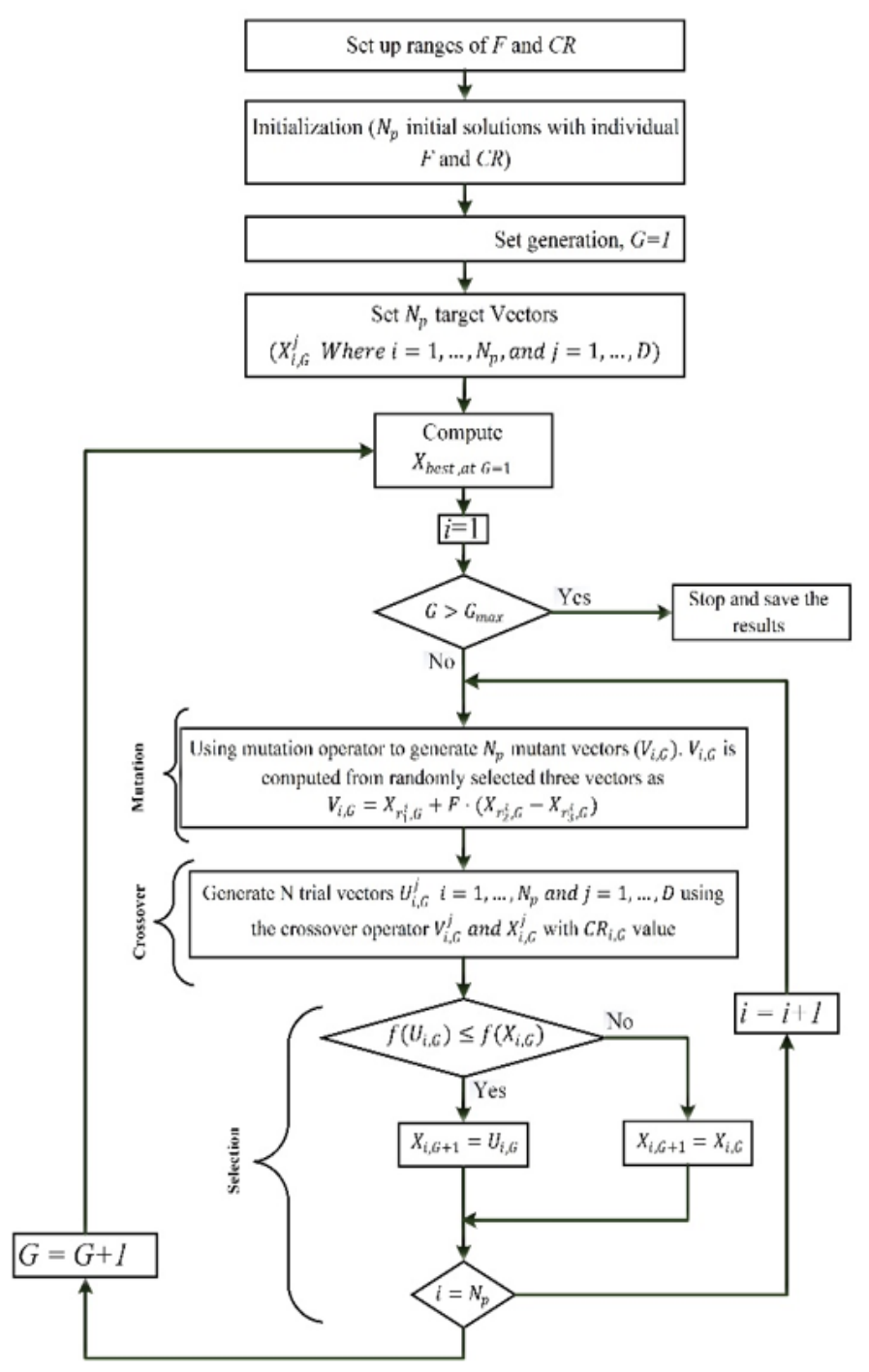

Fig. 2: Details of SaDE method

\subsection{Mutant Vector}

After initialization at each generation $G$, it generates mutant vector $V_{i, G}^{j}$ (from individual $X_{i, G}^{j}$ ). Three most widely used mutation strategies suggested in [28] are used in $\mathrm{SaDE}$ code which are given as follows.

$$
\begin{gathered}
V_{i, G}=X_{r_{1}^{i}, G}+F \times\left(X_{r_{2}^{i}, G}-X_{r_{3}^{i}, G}\right) \\
V_{i, G}=X_{\text {best }, G}+F \times\left(X_{r_{1}^{i}, G}-X_{r_{2}^{i}, G}\right)
\end{gathered}
$$

$V_{i, G}=X_{i, G}+F \times\left(X_{\text {best }, G}-X_{i, G}\right)+F \times\left(X_{r_{1}^{i}, G}-X_{r_{2}^{i}, G}\right)$

In Equation 23-27, $r_{1}^{i}$ to $r_{5}^{i}$ are distinct integer values arbitrary selected from present population in the range of $[1, N P]$ and are different. $X_{\text {best }, G}$ shows the best target vector at generation $G$ in the entire population. 


\begin{tabular}{|c|c|c|c|c|c|}
\hline 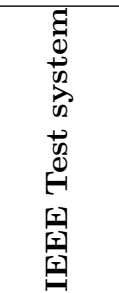 & 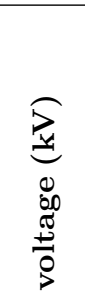 & 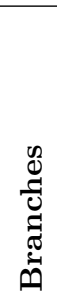 & 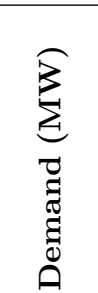 & 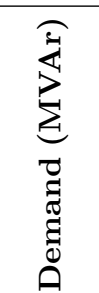 & 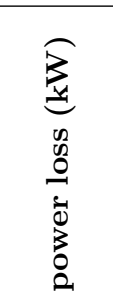 \\
\hline 33-bus & 12.66 & 37 & 3.72 & 2.3 & 210.998 \\
\hline 69-bus & 12.6 & 73 & 3.8 & 2.69 & 224.9 \\
\hline 119-bus & 11 & 132 & 22.709 & 17.041 & 1298.1 \\
\hline
\end{tabular}

TABLE 1: Data of standard radial distribution networks

\subsection{Binomial Crossover}

Competitive binomial crossover operation is performed between target vector $\left(V_{i, G}^{j}\right)$ and mutant vector $\left(X_{i, G}^{j}\right)$ for the generation of trial vector. For the effective generation of the trail vector $U_{i, G}$, the proposed $\mathrm{SaDE}$ algorithm employs the approach candidate pool. The three commonly used trial vector building methodologies as given in Equation 23-25 are used for the strategic candidate pool.

$\mathrm{DE} / \mathrm{rand} / 1 / \mathrm{bin}$

$\mathrm{DE} /$ rand-to-best/ $2 /$ bin

$\mathrm{DE} / \mathrm{rand} / 2 /$ bin

Where, DE means differential evolution, rand shows the random population member which is subtracted from the member of current population, 1 or 2 means one difference or two difference, rand-to-best means difference of current population from the best population member.

\subsection{Selection}

Next population $X_{i, G+1}$ is the selection between target vector and trial vector defined by:

$$
X_{i, G+1}=\left\{\begin{array}{lc}
U_{i, G}, & \text { if } f\left(U_{i, G}\right) \leq f\left(X_{i, G}\right) \\
X_{i, G}, & \text { otherwise. }
\end{array}\right.
$$

The details of the SaDE algorithm can be found in [28].

\section{Simulation Results}

For the optimal capacity and allocation of various types of DG, three distribution networks, such as 33, 69 and 119-bus, are considered to test efficiency of the proposed algorithm. For this purpose, various preparations along with single and multiple DGs setup are observed. Table 1 gives the technical details of the proposed test systems and the data of these systems is taken from [29]. Following two cases are considered to solve the problem of DG allocation: (i) single DG allocation, and (ii) multiple DG allocation. The summary

\begin{tabular}{|c|c|c|c|c|}
\hline $\begin{array}{c}\text { Test } \\
\text { system }\end{array}$ & $\begin{array}{c}\text { Case } \\
\text { no. }\end{array}$ & $\begin{array}{c}\text { Explanation } \\
\text { of study case }\end{array}$ & $\begin{array}{c}\text { No. of } \\
\text { DGs } \\
\text { (type) }\end{array}$ & $\begin{array}{c}\text { Min-max } \\
\text { DG } \\
\text { injection }\end{array}$ \\
\hline \multirow{3}{*}{ 33-bus } & Case I & $\begin{array}{c}\text { Single DG } \\
\text { allocation } \\
\text { at each bus }\end{array}$ & 1 & $\begin{array}{c}\text { o.2 to 2.8 } \\
\text { MW }\end{array}$ \\
\cline { 2 - 5 } 69-bus & Case II & $\begin{array}{c}\text { Multiple DG } \\
\text { allocation }\end{array}$ & 3 & $\begin{array}{c}0.2 \text { to 2.8 } \\
\text { MW }\end{array}$ \\
\cline { 2 - 5 } & Case I & $\begin{array}{c}\text { Single DG } \\
\text { allocation }\end{array}$ & 1 & $\begin{array}{c}0.2 \text { to } 2.8 \\
\text { MW }\end{array}$ \\
\hline \multirow{2}{*}{ 119-bus II } & $\begin{array}{c}\text { Multiple DG } \\
\text { allocation }\end{array}$ & 3 & $\begin{array}{c}0.2 \text { to 2.8 } \\
\text { MW }\end{array}$ \\
\cline { 2 - 5 } & Case I & $\begin{array}{c}\text { Single DG } \\
\text { allocation }\end{array}$ & 1 & $\begin{array}{c}0.2 \text { to 20 } \\
\text { MW }\end{array}$ \\
\cline { 2 - 5 } & Case II & $\begin{array}{c}\text { Multiple DG } \\
\text { allocation }\end{array}$ & 7 & $\begin{array}{c}0.2 \text { to 20 } \\
\text { MW }\end{array}$ \\
\hline
\end{tabular}

TABLE 2: Proposed test systems and study cases

\begin{tabular}{|c|c|c|c|}
\hline $\begin{array}{c}\text { Parameter } \\
\text { Name }\end{array}$ & Value & $\begin{array}{c}\text { Parameter } \\
\text { Name }\end{array}$ & Value \\
\hline Population (Np) & 100 & Max_fun_eval & 10,000 \\
\hline Max_gen (Gmax) & 100 & Ranges of F and CR & {$[0,1]$} \\
\hline
\end{tabular}

TABLE 3: Parameters of SaDE Algorithm

of all study cases is shown in Table 2 . In the above case studies, Table 3 shows the parameters of the proposed algorithm (SaDE). DG injection must be within the desirable limit. In case of high-power injection by DG, distribution network can become an active network and may cause large power losses, rises fault currents and many other counter effects. Therefore, DGs site, size and number must be carefully checked at the time when installed into distribution network.

\subsection{Case I: Allocation of single DG}

In this case all buses are chosen one by one for the selection of best capacity of DG. The bus which has the lowest RPL will be the candidate bus for DG allocation. Whereas. the rating at which power loss is minimum will be the optimal size of DG. In this case, two different types of DG are considered such as PV and WT. The response of the proposed technique for case 1 of IEEE 33-bus test system is as shown in Figure 3.

Figure 3 shows that the best position and capacity for Solar PV type DG is at bus 6 and $2.575 \mathrm{MW}$. It is because at this bus, losses are minimum up to 103.02 $\mathrm{kW}$. In Solar PV type DG case, losses are reduced from $203.7 \mathrm{~kW}$ to $103.02 \mathrm{~kW}$, resulting in a reduction of $49.01 \%$. However, top distribution of WT type DG functioning at 0.95 p.f lagging is at bus 6 and 2.8244 MW, respectively. It is due to the fact that the real power losses are minimum up to $63.67 \mathrm{~kW}$ resulting in percentage reduction of $64.84 \%$. Furthermore, Table 4 


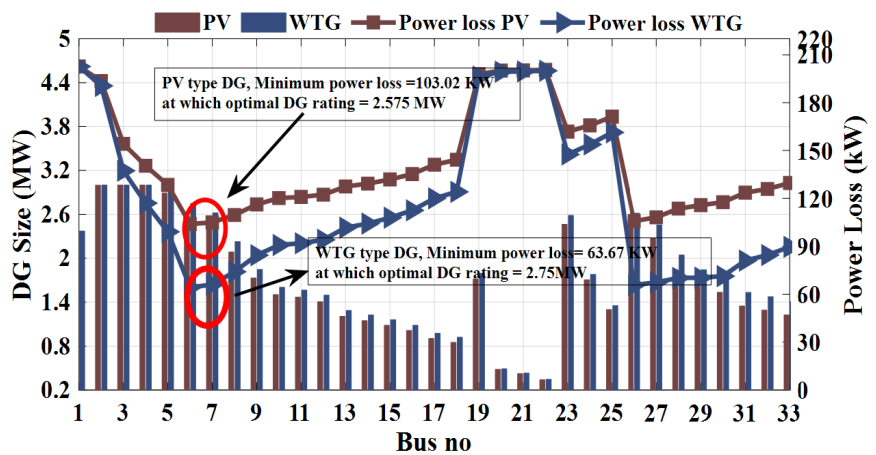

Fig. 3: Power loss and installation of DG in IEEE 33bus.

\begin{tabular}{|c|c|c|c|c|c|}
\hline Method & $\begin{array}{c}\text { DG } \\
\text { type }\end{array}$ & p.f & $\begin{array}{c}\text { Opti- } \\
\text { mal } \\
\text { Bus }\end{array}$ & $\begin{array}{c}\text { Size } \\
\text { DG } \\
(\mathbf{M W})\end{array}$ & $\begin{array}{c}\text { Losses } \\
(\mathbf{k W})\end{array}$ \\
\hline \multirow{2}{*}{ ALGA $[11]$} & PV & 1 & 6 & 2.58 & 105.4 \\
\cline { 2 - 6 } & WT & 0.95 & 6 & 2.978 & 72.68 \\
\hline BFO [30] & PV & 1 & 6 & 2.2 & 113.14 \\
\hline Analytical $[31]$ & PV & 1 & 6 & 2.49 & 111.24 \\
\hline \multirow{2}{*}{ SaDE } & PV & $\mathbf{1}$ & $\mathbf{6}$ & $\mathbf{2 . 5 7 5}$ & $\mathbf{1 0 3 . 0 2}$ \\
\cline { 2 - 6 } & WT & $\mathbf{0 . 9 5}$ & $\mathbf{6}$ & $\mathbf{2 . 7 5 0}$ & $\mathbf{6 3 . 6 7}$ \\
\hline
\end{tabular}

TABLE 4: Comparison of optimal allocation of 33-bus

displays the evaluation of th proposed algorithm with two other recent methods.

It can be noticed from Table 4 that the proposed technique has lowest losses compared to other techniques in both solar PV and WT generators. Similarly, Figure 4 shows the response of SaDE for 69-bus network.

Figure 4 gives the ideal position and capacity of Solar $\mathrm{PV}$ at bus 61 and $1.872 \mathrm{MW}$, respectively. It is because at this bus, losses are minimized up to $83.2 \mathrm{~kW}$. In Solar PV type, DG case losses are decreased from 224.6 $\mathrm{kW}$ to $83.2 \mathrm{~kW}$, resulting in percentage reduction of $62.97 \%$. Whereas, WT type DG working at 0.95 p.f

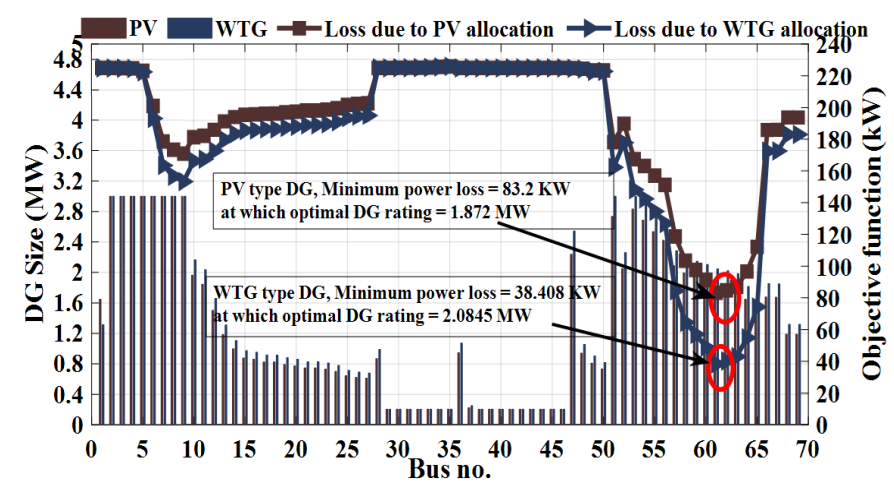

Fig. 4: Loss minimization and installation of DG individual in 69 -bus

\begin{tabular}{|c|c|c|c|c|c|}
\hline \multirow{2}{*}{ Method } & $\begin{array}{c}\text { DG } \\
\text { type }\end{array}$ & p.f & $\begin{array}{c}\text { Opti- } \\
\text { mal } \\
\text { bus }\end{array}$ & $\begin{array}{c}\text { DG } \\
(\mathbf{M W})\end{array}$ & $\begin{array}{c}\text { Power } \\
\text { loss } \\
(\mathbf{k W})\end{array}$ \\
\hline \multirow{2}{*}{ ALGA [11] $]$} & PV & 1 & 61 & 1.872 & 83.2 \\
\cline { 2 - 6 } & WTG & $\begin{array}{c}0.95 \\
\text { lag }\end{array}$ & 61 & 2.1555 & 38.46 \\
\hline $\begin{array}{c}\text { Analy- } \\
\text { tical [31] }\end{array}$ & PV & 1 & 61 & 1.8078 & 83.372 \\
\hline \multirow{2}{*}{ SaDE } & PV & $\mathbf{1}$ & $\mathbf{6 1}$ & $\mathbf{1 . 8 7 2}$ & $\mathbf{8 3 . 2}$ \\
\cline { 2 - 6 } & WTG & $\begin{array}{c}\mathbf{0 . 9 5} \\
\text { lag }\end{array}$ & $\mathbf{6 1}$ & $\mathbf{2 . 0 4 8 5}$ & $\mathbf{3 8 . 4 0 8}$ \\
\hline
\end{tabular}

TABLE 5: Allocation of DG size and site for 69-Bus

\begin{tabular}{|c|c|c|c|c|c|}
\hline \multirow{2}{*}{ Method } & $\begin{array}{c}\text { DG } \\
\text { type }\end{array}$ & p.f & $\begin{array}{c}\text { Opti- } \\
\text { mal } \\
\text { bus }\end{array}$ & $\begin{array}{c}\text { Size } \\
\text { of DG } \\
\text { (MW) }\end{array}$ & $\begin{array}{c}\text { Power } \\
\text { loss } \\
\text { (kW) }\end{array}$ \\
\hline ALGA & PV & 1 & 72 & 2.9828 & 1118.3 \\
\cline { 2 - 6 } & WTG & 0.95 & 72 & 3.3936 & 1041.3 \\
\hline $\begin{array}{c}\text { MTLBO } \\
{[32]}\end{array}$ & PV & 1 & 93 & 2.8714 & 1017.05 \\
\hline \multirow{2}{*}{ SaDE } & PV & $\mathbf{1}$ & $\mathbf{7 1}$ & $\mathbf{2 . 9 7 7}$ & $\mathbf{1 0 1 7 . 0 1}$ \\
\cline { 2 - 6 } & WTG & $\mathbf{0 . 9 5}$ & $\mathbf{7 1}$ & $\mathbf{3 . 2 1 9}$ & $\mathbf{9 4 0 . 0 5}$ \\
\hline
\end{tabular}

TABLE 6: Single site and site comparison of 119-bus

lagging is at bus 61 and $2.0845 \mathrm{MW}$ respectively. It is due to the fact that the real power losses are minimum up to $38.41 \mathrm{~kW}$ resulting in percentage reduction of $82.82 \%$. Furthermore, Table 5 gives the assessment of simulation outcomes of SaDE with other exiting techniques for IEEE 69-bus. Figure 5 shows the single DG allocation considering power loss minimization, where red encircle shows the minimum losses, rating and position.

Solar PV type DG is selected at bus 71 and 2.977 MW respectively. It is because at this bus, losses are minimum and decreased up to $1016.7 \mathrm{~kW}$ form 1400 $\mathrm{kW}$ base loss, resulting in a reduction of $27.37 \%$. For the finest sharing of WT type DG operational at 0.95 p.f, lagging is selected at bus 71 and $3.2190 \mathrm{MW}$ respectively. It is due to the fact that real power losses are minimum up to $940.05 \mathrm{~kW}$ ( $32.85 \%$ reduction). Table 6 gives the comparison of the proposed algorithm with other techniques for 119-bus

It can be noticed from Table 6 that for IEEE 119bus system, the proposed technique has lowest losses. DG size in both Solar PV and WTG DG is compared to ALGA [11] method. It is evident that the proposed technique has the ability to achieve the global minimum in the system. Furthermore, it may be noticed from Table 4-6 that the size of solar PV type DG is smaller than WTG type DG allocation. WTG type DG inject real as well as reactive power into the bus, whereas, solar PV inject only active power into the bus. Furthermore, due to high rating of WTG type 


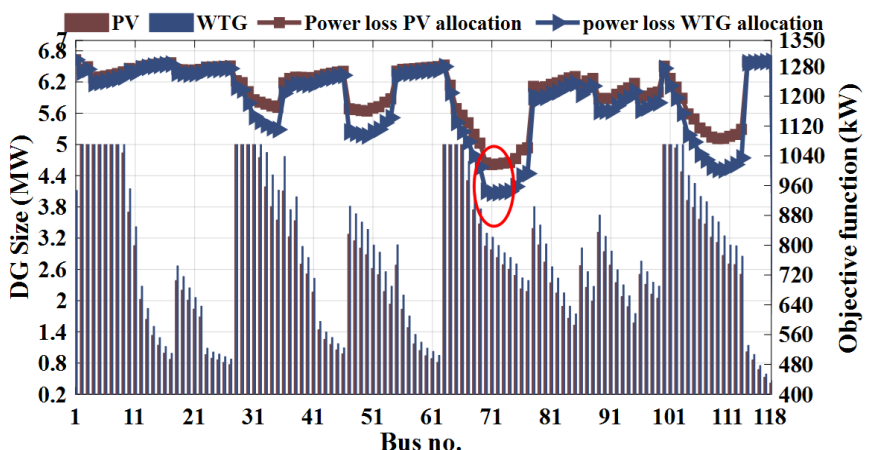

Fig. 5: IEEE 119-bus DG site and size selection

\begin{tabular}{|c|c|c|c|}
\hline Method & $\begin{array}{c}\text { Optimal } \\
\text { bus }\end{array}$ & $\begin{array}{c}\text { DG size (MW) } \\
=\text { sum } P D G\end{array}$ & $\begin{array}{c}\text { Losses } \\
(\mathrm{kW})\end{array}$ \\
\hline CTLBO [15] & $13,24,30$ & $\begin{array}{l}0.8017,1.0913 \\
1.0536=2.947\end{array}$ & 72.787 \\
\hline QOTLBO [33] & $12,24,29$ & $\begin{array}{l}0.8808,1.0592, \\
1.0714=3.011\end{array}$ & 74.101 \\
\hline FWA [19] & $14,18,32$ & $\begin{array}{c}0.5892,0.1895 \\
1.015=1.79\end{array}$ & 88.68 \\
\hline ACSA [18] & $14,24,30$ & $\begin{array}{c}0.7798,1.125, \\
1.3450=3.2498\end{array}$ & 74.26 \\
\hline UDVA [34] & $11,24,29$ & $\begin{array}{l}0.875,0.931 \\
0.925=2.73\end{array}$ & 74.21 \\
\hline SaDE & $24,14,30$ & $\begin{array}{c}1.1,0.75 \\
1.07=2.929\end{array}$ & 71.398 \\
\hline
\end{tabular}

TABLE 7: Comparison of three PV types DGs for 33bus

DG, its losses are lowest as compared to solar type DG.

\subsection{Case II: Allocation of Multiple DGs}

For the optimal DG allocation, results of 33, 69 and 119-bus test systems using proposed technique are presented in the following sections.

\subsubsection{Multiple DGs in IEEE 33-bus}

According to the literature, the number of of DGs that satisfy all the limits is three. In an attempt to show the usefulness of SaDE, its response is compared with other existing technique as shown in Table 7 . Without DG in base case, the system has losses of $203.7 \mathrm{~kW}$, however, with the addition of three DGs, system has losses of $71.398 \mathrm{~kW}$. This results in the decrease of $64.81 \%$ losses in the system. Thus, the proposed technique has the ability to find the global minimum of real power losses and DG size in the RDN. Moreover, the allocation of DGs also enhances the voltage profile of bus form $0.913 \mathrm{p} . \mathrm{u}$ to 0.9723 p.u, as shown in Figure 6. The Convergence of the proposed algorithm satisfies all the constraints, as shown in Figure 7.

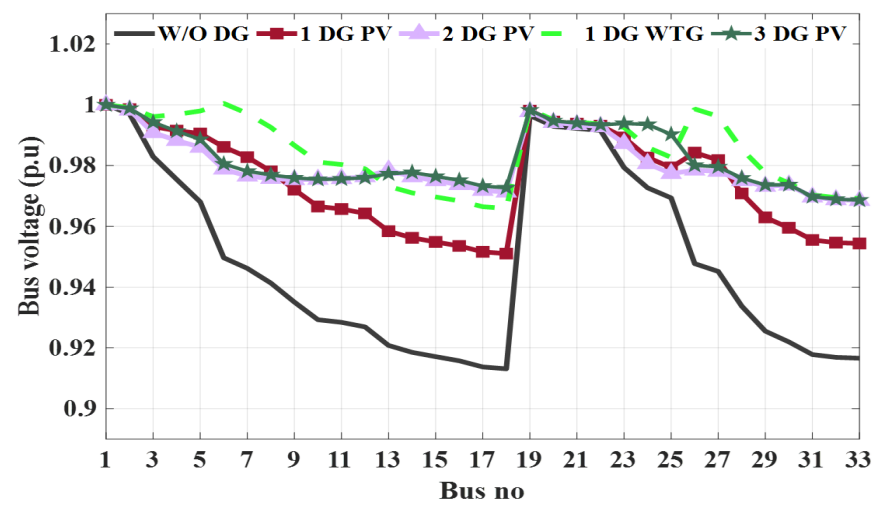

Fig. 6: 33-Bus voltage level

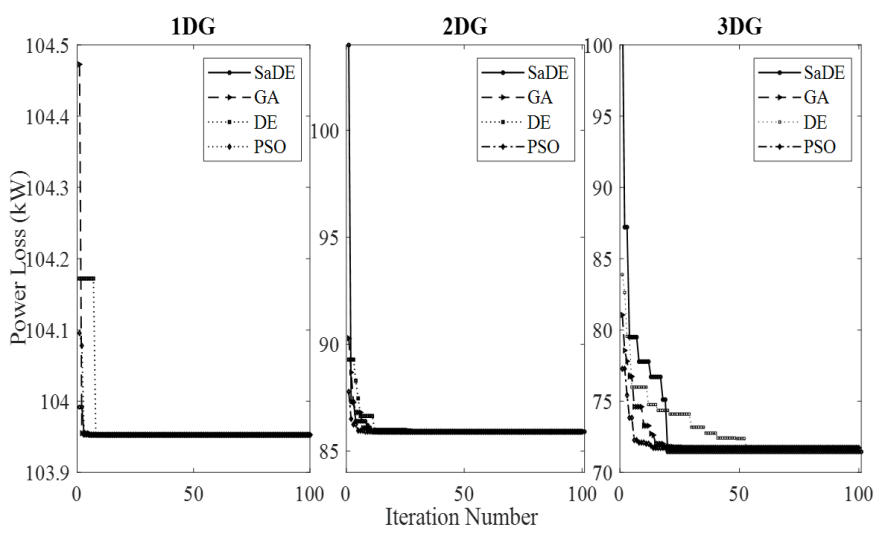

Fig. 7: Convergence of the objective function of 33-bus

\subsubsection{Multiple DGs in IEEE 69-Bus Network}

In this case, three DGs are found to satisfy all the limits for optimal site and size. Without DG, the system has a loss of of $224.6 \mathrm{~kW}$. However, with addition of three DGs, the system' loss reduced to $69.42 \mathrm{~kW}$. Thus, with the multiple DGs, system has lowest losses resulting in a power reduction of $70 \%$. In order to show the efficacy of the SaDE approach, its response is compared with other existing techniques, as shown in Table 8. Moreover the allocation of DGs is also found to enhance the voltage profile of bus form 0.9092p.u. to 0.9717 p.u, as shown in Figure 8. The convergence curve of power loss reduction is shown in Figure 9.

\subsubsection{Multiple DGs in 119-Bus Network}

In this case, four solar PV type DG satisfy all the limits for optimal site and size. without DGs, the system has losses of $1400 \mathrm{~kW}$. However, with addition 


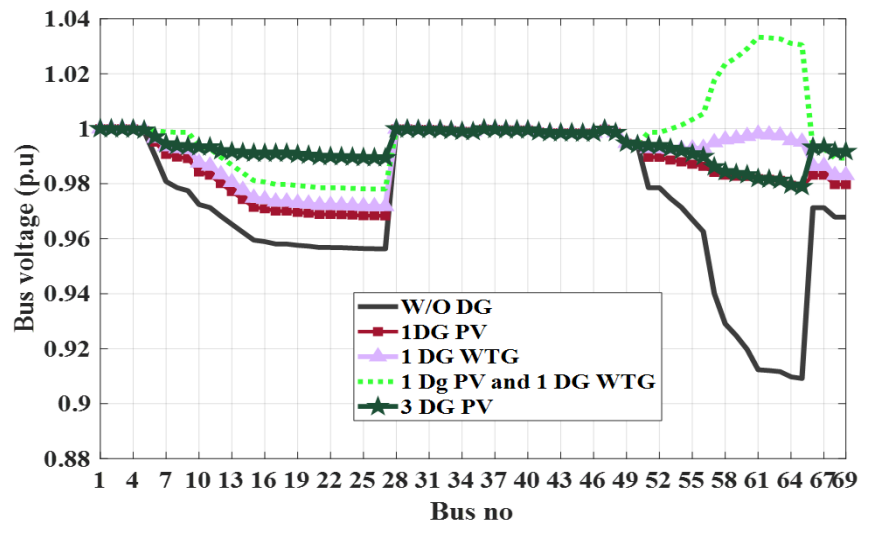

Fig. 8: 69-Bus voltage level

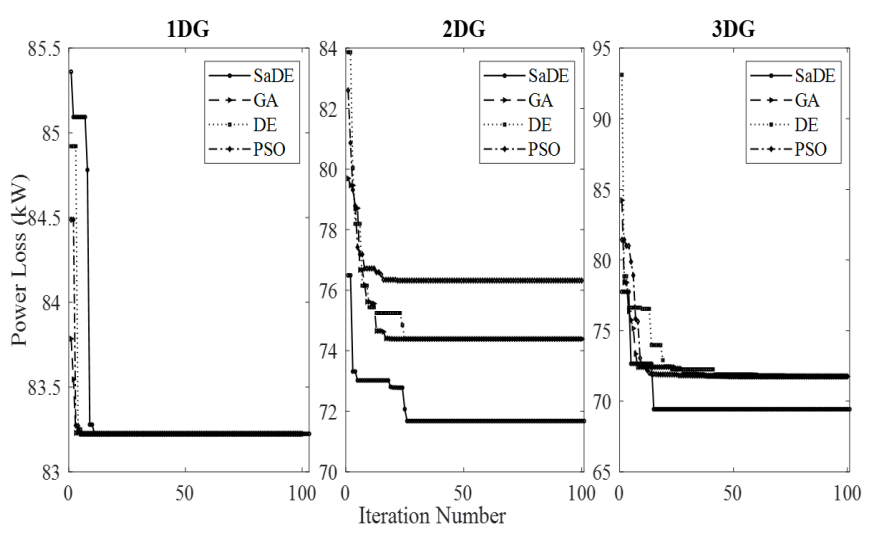

Fig. 9: Convergence of power loss reduction of 69-bus

of four DGs, the system has losses of $642.5 \mathrm{~kW}$, as shown in Figure 10. Thus, with multiple DGs, system has lowest losses resulting in a power reduction of $54.10 \%$. Moreover, the allocation of DGs also enhances the voltage profile of bus form 0.869 p.u. to 0.955p.u, as shown in Figure 11. In order to show the effectiveness of the proposed technique, its response is compared with other existing techniques as shown in Table 9. It can be noticed from Table 9 that the proposed technique has the lowest losses of 516.254 $\mathrm{kW}$ compared to other techniques.

\section{Discussion}

The simulation results of all standard IEEE redial test systems show that the minimum value of voltage at bus has been improved beyond smallest constraint limit following the optimal DG allocation. It can be observed from the simulation results that WTG DG injection decrease more RPL and enhances the value of voltage at each bus in comparison to solar PV type

\begin{tabular}{|c|c|c|c|}
\hline Method & $\begin{array}{c}\text { Optimal } \\
\text { bus }\end{array}$ & $\begin{array}{c}\text { Optimal size of } \\
\text { DG (MW) } \\
\text { =sum PDG }\end{array}$ & $\begin{array}{c}\text { Power } \\
\text { loss } \\
(\mathbf{k W})\end{array}$ \\
\hline CTLBO $[15]$ & $11,18,61$ & $\begin{array}{c}0.5268,0.3796, \\
1.7190=2.6254\end{array}$ & 69.388 \\
\hline QOTLBO [33] & $18,61,63$ & $\begin{array}{c}0.5334,1.1986, \\
0.5672=2.299\end{array}$ & 71.625 \\
\hline FWA [19] & $27,61,65$ & $\begin{array}{c}0.2258,1.199, \\
0.4085=1.833\end{array}$ & 77.85 \\
\hline ACSA [18] & $11,18,61$ & $\begin{array}{c}0.602,0.380, \\
2=2.982\end{array}$ & 72.44 \\
\hline UDVA [34] & $11,17,61$ & $\begin{array}{c}0.604,0.417, \\
1.410=2.43\end{array}$ & 72.63 \\
\hline SaDE & $\mathbf{6 1 , 1 8 , 1 1}$ & $\begin{array}{c}\mathbf{1 . 7 1 9} \mathbf{0 . 3 8 0} \\
\mathbf{0 . 5 2 6}=\mathbf{2 . 6 2 5}\end{array}$ & $\mathbf{6 9 . 4 2}$ \\
\hline
\end{tabular}

TABLE 8: Comparison of three PV types DGs for 69bus

\begin{tabular}{|c|c|c|c|}
\hline Method & $\begin{array}{c}\text { Optimal } \\
\text { bus }\end{array}$ & DG size (MW) & $\begin{array}{c}\text { losses } \\
(\mathbf{k W})\end{array}$ \\
\hline & 20,44, & $1.8176,1.2764$, & \\
CTLBO $[15]$ & 52,75, & $2.7671,2.5333$, & 516.256 \\
& 83,100, & $2.0949,1.6631$, & \\
& 114 & $3.1199=15.2723$ & \\
\hline & 24,42, & $1.2463,0.7322$, & \\
QOTLBO [33] & 47,74, & $3.5392,2.6792$, & 576.182 \\
& 78,94, & $1.2483,1.0865$, & \\
& 108 & $3.2432=13.774$ & \\
\hline & 8,10, & $1.7553,0.5910$, & \\
TLBO [33] & 36,49, & $1.5368,2.6865$, & 590.697 \\
& 71,79, & $2.5014,2.4941$, & \\
& 110 & $2.6628=14.227$ & \\
\hline \multirow{5}{*}{ SaDE } & $\mathbf{2 0 , 4 2 ,}$ & $\mathbf{1 . 8 1 7 6 , 1 . 2 7 6 4 ,}$ & \\
& $\mathbf{5 0 , 7 2 ,}$ & $\mathbf{2 . 7 6 7 1 , 2 . 5 3 3 3 ,}$ & $\mathbf{5 1 6 . 2 5 4}$ \\
& $\mathbf{8 0 , 9 6 ,}$ & $\mathbf{2 . 0 9 4 9 , \mathbf { 1 . 6 6 3 1 } ,}$ & \\
& $\mathbf{1 0 9}$ & $\mathbf{3 . 1 1 9 9}=\mathbf{1 5 . 2 7}$ & \\
\hline
\end{tabular}

TABLE 9: Comparison of three PV types DGs for 69bus

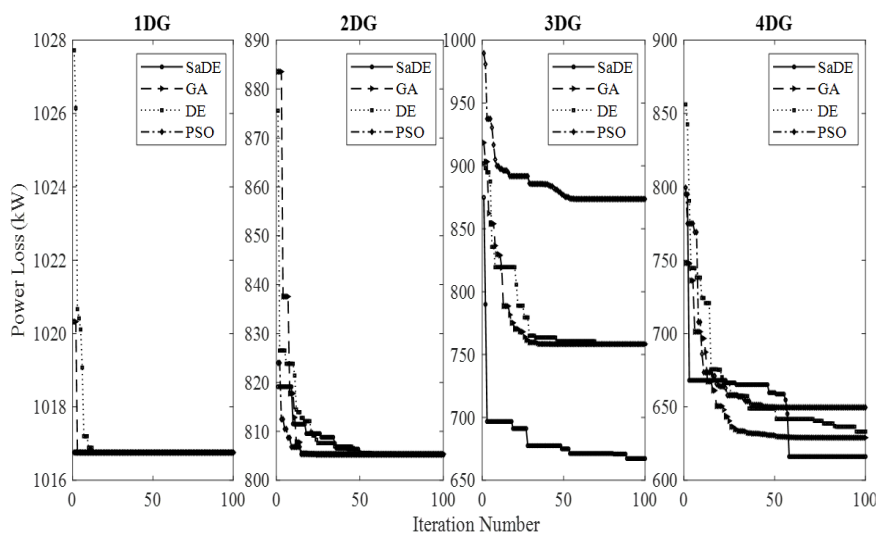

Fig. 10: Convergence curve of 119-Bus 


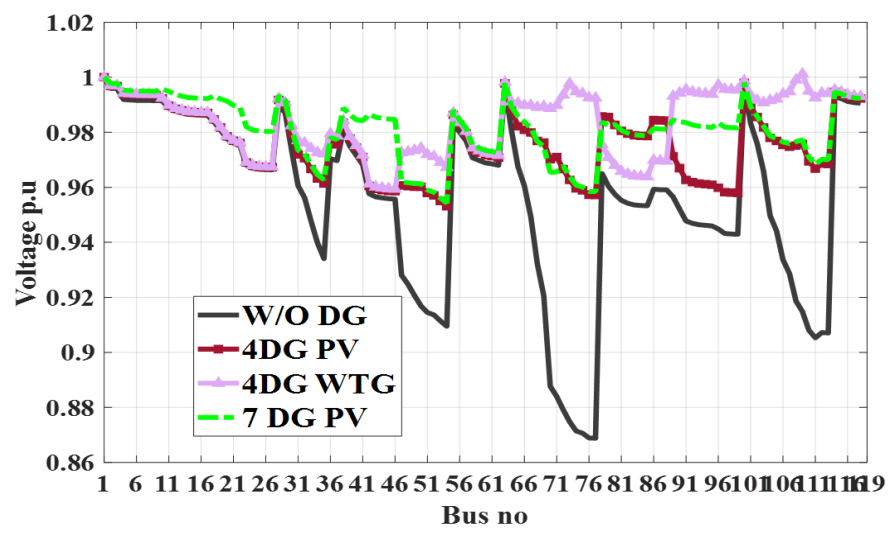

Fig. 11: 119-Bus voltage profile

DG. It is because WTG type DG has the ability to inject real as well as reactive power into the distribution system.

It may be noticed from the simulation results that the proposed technique is not only efficient for single DG allocation, but it is also effective for the multiple installation of the DGs compared to other methods such as GA, DE and PSO. In addition, comparison of the proposed technique performance with various other existing techniques has shown that the proposed technique has lowest losses and smallest DG size in both PV and WTG DG for single as well as multiple DG allocation. Hence, the proposed method has the ability to optimally improve voltage profile and minimize RPL for small to large scale RDNs by allocating the optimal site and size of DGs.

\section{Conclusion}

In this article, the optimization of power loss has been presented for the optimum site and size of DG allocation, considering WT and solar PV. The proposed SaDE algorithm has been validated on three standard IEEE RDN namely 33, 69 and 119-bus systems. The main objective of the proposed technique is to reduce losses with smallest DG size in both single and multiple DG allocation in distribution system. The simulation results have been presented for single and multiple DG allocation. Higher the enhancement in voltage level at each bus, higher the reduction in power loss. Furthermore, the allocation of WT results in a satisfactory enhancement in voltage profile as well as real power loss reduction for all standard RDN due to its ability of injecting reactive power at lagging p.f. The comparison of results of the proposed approach with other existing technique shows the superiority of $\mathrm{SaDE}$ algorithm. Thus, the proposed SaDE technique can be applied to any size of radial distribution system.

\section{Acknowledgement}

This research is funded by Quaid-e-Awam University of Engineering Science \& Technology Nawabshah, Sindh, Pakistan.

\section{References}

[1] G. Pepermans, J. Driesen, D. Haeseldonckx, R. Belmans, and W. D'haeseleer, "Distributed generation: definition, benefits and issues," Energy Policy, vol. 33, no. 6, pp. 787$798,2005$.

[2] T. N. Shukla, S. P. Singh, V. Srinivasarao, and K. B. Naik, "Optimal Sizing of Distributed Generation Placed on Radial Distribution Systems," (in English), Electric Power Components and Systems, vol. 38, no. 3, pp. 260-274, 2010.

[3] R. Viral and D. K. Khatod, "An analytical approach for sizing and siting of DGs in balanced radial distribution networks for loss minimization," International Journal of Electrical Power \& Energy Systems, vol. 67, pp. 191-201, 2015.

[4] T. Gozel, M. H. Hocaoglu, U. Eminoglu, and A. Balikci, "Optimal placement and sizing of distributed generation on radial feeder with different static load models," in 2005 International Conference on Future Power Systems, pp. 2 pp.1-6, 2005.

[5] W. Caisheng and M. H. Nehrir, "Analytical approaches for optimal placement of distributed generation sources in power systems," IEEE Transactions on Power Systems, vol. 19, no. 4, pp. 2068-2076, 2004.

[6] K. M. Muttaqi, A. D. T. Le, M. Negnevitsky, and G. Ledwich, "An Algebraic Approach for Determination of DG Parameters to Support Voltage Profiles in Radial Distribution Networks," IEEE Transactions on Smart Grid, vol. 5, no. 3, pp. 1351-1360, 2014.

[7] S. N. G. Naik, D. K. Khatod, and M. P. Sharma, "Analytical approach for optimal siting and sizing of distributed generation in radial distribution networks," IET Generation, Transmission \& Distribution, vol. 9, no. 3, pp. 209-220, 2015.

[8] R. S. A. Abri, E. F. El-Saadany, and Y. M. Atwa, "Optimal Placement and Sizing Method to Improve the Voltage Stability Margin in a Distribution System Using Distributed Generation," IEEE Transactions on Power Systems, vol. 28, no. 1, pp. 326-334, 2013.

[9] M. Ettehadi, H. Ghasemi, and S. Vaez-Zadeh, "Voltage Stability-Based DG Placement in Distribution Networks," IEEE Transactions on Power Delivery, vol. 28, no. 1, pp. 171-178, 2013.

[10] T. R. Ayodele, A. S. O. Ogunjuyigbe, and O. O. Akinola., "Optimal Location, Sizing, and Appropriate Technology Selection of Distributed Generators for Minimizing Power Loss Using Genetic Algorithm," Journal of Renewable Energy 2015, 2015.

[11] F. H. F. A. A. Hassan, A. Nafeh, and M. A. Abu-Elmagd, "Genetic single objective optimisation for sizing and allocation of renewable DG systems," International Journal of Sustainable Energy,, vol. 36 no. 6, pp. 545-562, 2017.

[12] F. Ugranlı and E. Karatepe, "Optimal wind turbine sizing to minimize energy loss," International Journal of Electrical Power \& Energy Systems, vol. 53, pp. 656-663, 2013.

[13] R. K. Singh and S. K. Goswami, "Optimum Siting and Sizing of Distributed Generations in Radial and Networked Systems," Electric Power Components and Systems, vol. 37, no. 2, pp. 127-145, 2009. 
[14] J.-N. Sheen, M.-T. Tsai, and S.-W. Wu, "A benefits analysis for wind turbine allocation in a power distribution system," Energy Conversion and Management, vol. 68, pp. 305-312, 2013.

[15] I. A. Quadri, S. Bhowmick, and D. Joshi, "A comprehensive technique for optimal allocation of distributed energy resources in radial distribution systems," Applied Energy, vol. 211, pp. 1245-1260, 2018.

[16] M. Kefayat, A. Lashkar Ara, and S. A. Nabavi Niaki, "A hybrid of ant colony optimization and artificial bee colony algorithm for probabilistic optimal placement and sizing of distributed energy resources," Energy Conversion and Management, vol. 92, pp. 149-161, 2015.

[17] P. P. Biswas, R. Mallipeddi, P. N. Suganthan, and G. A. J. Amaratunga, "Optimal reconfiguration and distributed generator allocation in distribution network using an advanced adaptive differential evolution," in 2017 IEEE Symposium Series on Computational Intelligence (SSCI), 2017, pp. 1-7.

[18] T. T. Nguyen, A. V. Truong, and T. A. Phung, "A novel method based on adaptive cuckoo search for optimal network reconfiguration and distributed generation allocation in distribution network," International Journal of Electrical Power \& Energy Systems, vol. 78, pp. 801-815, 2016.

[19] A. Mohamed Imran, M. Kowsalya, and D. P. Kothari, "A novel integration technique for optimal network reconfiguration and distributed generation placement in power distribution networks," International Journal of Electrical Power \& Energy Systems, vol. 63, pp. 461-472, 2014.

[20] D. Q. Hung and N. Mithulananthan, "Multiple Distributed Generator Placement in Primary Distribution Networks for Loss Reduction," IEEE Transactions on Industrial Electronics, vol. 60, no. 4, pp. 1700-1708, 2013.

[21] R. S. Rao, K. Ravindra, K. Satish, and S. V. L. Narasimham, "Power Loss Minimization in Distribution System Using Network Reconfiguration in the Presence of Distributed Generation," IEEE Transactions on Power Systems, vol. 28, no. 1, pp. 317-325, 2013.

[22] W. H. Kersting, Distribution system modelling and analysis. New Mexico: CRC Press, 2002.

[23] T. Gözel and M. H. Hocaoglu, "An analytical method for the sizing and siting of distributed generators in radial systems," Electric Power Systems Research, vol. 79, no. 6, pp. 912-918, 2009.

[24] N. Kanwar, N. Gupta, K. R. Niazi, and A. Swarnkar, "Improved meta-heuristic techniques for simultaneous capacitor and DG allocation in radial distribution networks," International Journal of Electrical Power \& Energy Systems, vol. 73, pp. 653-664, 2015.

[25] "IEEE Standard for Interconnection and Interoperability of Distributed Energy Resources with Associated Electric Power Systems Interfaces-Amendment 1: To Provide More Flexibility for Adoption of Abnormal Operating Performance Category III," IEEE Std 1547a-2020 (Amendment to IEEE Std 1547-2018), pp. 1-16, 2020.

[26] Y. M. Atwa, E. F. El-Saadany, M. M. A. Salama, and R. Seethapathy, "Optimal Renewable Resources Mix for Distribution System Energy Loss Minimization," (in English), Ieee Transactions on Power Systems, vol. 25, no. 1, pp. 360370, 2010.

[27] K. Price, R. M. Storn, and J. A. Lampinen, Differential evolution: a practical approach to global optimization. Springer Science \& Business Media, 2006.

[28] A. K. Qin, V. L. Huang, and P. N. Suganthan, "Differential Evolution Algorithm With Strategy Adaptation for Global
Numerical Optimization," IEEE Transactions on Evolutionary Computation, vol. 13, no. 2, pp. 398-417, 2009.

[29] R. D. Zimmerman, C. E. Murillo-Sanchez, and R. J. Thomas, "MATPOWER: Steady-State Operations, Planning, and Analysis Tools for Power Systems Research and Education," IEEE Transactions on Power Systems, vol. 26, no. 1, pp. 12-19, 2011.

[30] K. R. Devabalaji and K. Ravi, "Optimal size and siting of multiple DG and DSTATCOM in radial distribution system using Bacterial Foraging Optimization Algorithm," Ain Shams Engineering Journal, vol. 7, no. 3, pp. 959-971, 2016.

[31] N. Acharya, P. Mahat, and N. Mithulananthan, "An analytical approach for DG allocation in primary distribution network," International Journal of Electrical Power \& Energy Systems, vol. 28, no. 10, pp. 669-678, 2006.

[32] J. A. M. Garcia and A. J. G. Mena, "Optimal distributed generation location and size using a modified teachinglearning based optimization algorithm," (in English), International Journal of Electrical Power \& Energy Systems, vol. 50, pp. 65-75, Sep 2013.

[33] S. Sultana and P. K. Roy, "Multi-objective quasioppositional teaching learning based optimization for optimal location of distributed generator in radial distribution systems," International Journal of Electrical Power \& Energy Systems, vol. 63, pp. 534-545, 2014.

[34] A. Bayat, A. Bagheri, and R. Noroozian, "Optimal siting and sizing of distributed generation accompanied by reconfiguration of distribution networks for maximum loss reduction by using a new UVDA-based heuristic method," International Journal of Electrical Power \& Energy Systems, vol. 77, pp. 360-371, 2016. 